\title{
Administrative Workload and its Relationship with Psychological Pressure Among Coaches of Some Fitness Centers
}

\author{
Hasan Mohammed Al-Khaldi \\ The Hashemite University, Zarqa, Jordan \\ Coaching and Sport Management Department
}

\begin{abstract}
The study aimed at identifying administrative workload and its relationship with psychological pressure among some coaches at fitness centers in Jordan. The study was conducted on a sample of (50). A measure was developed for administrative workload and its relationship with psychological pressure. The most important results were that the level of psychological pressure among coaches of both genders in some fitness centers in Amman was high and that the administrative workload has a strong correlation relationship with psychological pressure among the sample members. The most important recommendation were the need to reduce administrative workload of coaches of both genders as well as and the need to provide a suitable work environment in order to reduce that psychological pressure.
\end{abstract}

\section{Introduction}

A coach is considered one of the educational figures in charge of leading the training and education process. He influences the individual character's development in a balanced, comprehensive way whether the individual was an athlete or not, it depends also on the trainer's characteristics, abilities, knowledge, information and skills in his field. The coach must be a role model, likes and is dedicated to his job. He spends a lot of time developing himself as to his skills and knowledge in order to enhance the training process. The trainer's obligations are considerable and significant, besides training customers and players in sports clubs or fitness centers; he is responsible for developing himself concerning skill, theoretical and practical aspect, in addition to spreading awareness among the members of the society. He must be familiar with scientific knowledge and information, and learn about updates in his work field. Moreover, he must know the sport administrative means and familiarize himself with the foundation and base of dealing with the human factor particularly given that many sports club or fitness centers engage the coach in the administrative work such as organization, contribution in planning or even managing the human factor in the gym or center. Sometimes, they engage the trainer in processes related to Marketing (Honeycutt.2000; Watson, (2005).

Considering the workload in the sports club or fitness center and the size of burden on the coach including the training, administrative, social and marketing processes in addition to the pressures that her faces in life generally, all of these made the individual lives in tension and frustration which leads to anxiety and sometimes self-respect. (Ahmad and Mahmood, 2009). Given the importance of work stress, this subject has become one of the primary interests for many administrative intellectuals. Work stress as:" any present features in the work environment, which creates a complex for the worker. Job pressure is as a group of negative factors that exist in the work environment which makes work a hard and distasteful process .Wong AC. (2012) . One of these factors is the confusion of role, the conflict of role, poor working conditions and workload. (Schiffman, L., and Kounk, 2000). Administrative Workload is the amount of work to be performed by the individual (coach) during the day, week and month, and includes particular works accurately related to his work as well as other additional works (Bohlander, et al 2007 ).

The pressures on the worker (coach) whether in the sports club or the fitness center results in several negative effects such as - increase in financial costs (being late for work, absence, work stoppage, employing additional trainers), low level of responsibility, loss of focus at work, high level of complaints by players and costumers, drop-out, looking for new job, and sense of failure. Psychological Pressure means that the factors or conditions in the work environment which create a threat to the continuity of the individual at work. Cheng (2009).

Fitness centers are a place where many community segments gather, hoping to achieve the best results, whether physical, recreational, therapeutic or even training. This requires that the fitness centers are significantly interested in providing a safe, secure and suitable environment for the work of coaches. This study attempts to identify the nature of the relationship between important variables that have a significant and effective role in the training process at the fitness center through identifying the administrative workload on the coach at the fitness center and its relationship to psychological pressure. 
The researcher observed through his dealings with field training students in fitness centers and through his field trips and visits that fitness centers are primarily concerned with making the material profit and appointing a limited number of coaches of both genders in order to reduce expenses. More importantly, they increase workload of coaches in fitness centers. Therefore, their role is not limited to training, but also extends to a set of parallel administrative works, which has become a source of pressure for many of them. The researcher also noticed through his observation that the coaches in the fitness centers are continuously looking for another job to provide them with better work conditions and workload in their field of specialization.

According to the researcher's knowledge, the significance of the study is highlighted as being the first study that examines administrative workload and its relationship with psychological pressure among coaches of some larges fitness centers in Jordan. This study also reveals the level of administrative workload of coaches, indicating the reason behind avoiding work in fitness centers or looking continuously for other job opportunities in fitness centers inside or outside Jordan, which assists in reducing the problem. This study will help officials in the fitness centers to identify the reality of the situation and act accordingly. Moreover, the significance of the study is that these coaches deal with different community segments, hoping to achieve the best results, whether physical, training, recreational or therapeutic, and that their work is related to production and profits.

\section{Study Objectives:}

The study aimed at identifying the following:

1. The level of psychological pressure among coaches of some fitness centers in Amman - Jordan.

2. The administrative workload and its relationship with psychological pressure.

3. There are differences among both genders in the level of psychological pressure.

\section{Study Questions:}

1. What is the level of psychological pressure among coaches of some fitness centers in Amman - Jordan?

2. What is the relationship between administrative workload and psychological pressure among coaches of some fitness centers in Amman - Jordan?

3. Are there statistically significant differences in the level of psychological pressure attributed to the gender variable?

\section{Study Methodology:}

The researcher has used the descriptive approach commensurate with the nature of the study.

\section{Study Sample:}

The study sample consisted of coaches of some fitness centers in Amman - Jordan. There are (12) male and (38) female coaches. Table (1) shows distribution of the study sample.

\section{Table (1): Distribution of the Study Sample.}

\begin{tabular}{|l|l|l|l|}
\hline \multirow{2}{*}{ Fitness Center } & \multicolumn{2}{c|}{ Gender } & \multirow{2}{*}{ Total } \\
\cline { 2 - 4 } & Female & Male & 16 \\
\hline Fitness First & 12 & 4 & 8 \\
\hline Viga Fitness & 6 & 2 & 15 \\
\hline Golden's & 12 & 3 & 11 \\
\hline Dead sea hotels & 8 & 3 & 50 \\
\hline Total & 38 & 12 & $100 \%$ \\
\hline Percentage & $76 \%$ & $24 \%$ & \\
\hline
\end{tabular}

\section{Study Tool:}

After reviewing many previous studies and Arab and foreign theoretical literature related to the subject matter, the researcher designed a measure consisting of (53) paragraphs divided into eight areas (fitness center area, psychological pressure area, relationship with community, relationship with colleagues, relationship with administrative aspects, relationship with other gender, communication, feelings, future planning).

\section{Validity of the Tool:}

The researcher presented the measure he designed to experts in the field of sports management and psychology to give their observations regarding paraphrasing, the number of paragraphs and the appropriateness of paragraphs to the study areas. Accordingly, (11) paragraphs of the psychological pressure measure were omitted, bringing the number of paragraphs in the measure to (42) in its final form. 


\section{Reliability of the Tool:}

Table (2).The researcher carried out reliability of the study tool as shown

\begin{tabular}{|l|l|l|l|l|l|l|}
\hline \multirow{2}{*}{$\begin{array}{l}\text { Reliability } \\
\text { Methods }\end{array}$} & \multicolumn{4}{|l|}{ Split - Half } & \multicolumn{4}{l|}{ Cronbach's Alpha } & \multicolumn{2}{l|}{ Test - Retest } \\
\cline { 2 - 7 } & R Value & Sig. & R Value & Sig & R Value & Sig \\
\hline Measure & 0.72 & 0.01 & 0.82 & 0.02 & 0.88 & 0.01 \\
\hline
\end{tabular}

\section{Statistical Processing:}

The research carried out the statistical processing in accordance with the nature of the study through using Pearson correlation coefficient and one - way analysis of variance (ANOVA).

\section{Results and Discussion:}

The first question was "What is the level of psychological pressure among coaches of some fitness centers in Amman Jordan?".

To answer this question, the area of each level was determined by the scores obtained from the psychological pressure measure applied in the study as shown in Table (3).

Table (3): The Level of Psychological Pressure among the Sample Members.

\begin{tabular}{|l|l|l|l|l|l|l|}
\hline \multirow{2}{*}{ Level } & \multicolumn{2}{|l|}{ Low } & Medium & \multicolumn{2}{l|}{ High } \\
\cline { 2 - 7 } & Frequency & Percentage & Frequency & Percentage & Frequency & Percentage \\
\hline $\begin{array}{l}\text { Scores of the } \\
\begin{array}{l}\text { Sample } \\
\text { Members }\end{array}\end{array}$ & 2 & $4 \%$ & 12 & $24 \%$ & 36 & $72 \%$ \\
\hline
\end{tabular}

Table (3) shows that the level of psychological pressure among coaches of some fitness centers in Amman - Jordan was high with $(72 \%)$ percentage.

The researcher indicated that coaches in fitness centers may be required to perform many workloads through carrying out their training task as a main part. It may be due to the need to attract other customers to the center or because they are engaged with the administrators of the centers in the planning, organization and marketing. In addition, it may be because they through performing their administrative workloads find it difficult to carry out their training tasks due to their poor qualifications. The favoritism in employment may also be considered a main reason for this; as some coaches have work tasks more than others. AlByrqdar, Tanheed (2011) pointed out that the cumulative work pressure among individuals, even if they are qualified, leads to high psychological pressure, resulting in disappointment and psychological disorder.

The second question was "What is the relationship between administrative workload and psychological pressure among coaches of some fitness centers in Amman - Jordan?".

To answer this question, Pearson correlation coefficient was used as shown in Table (4).

Table (4): Administrative Workload and its Relationship with Psychological Pressure among the Study Sample.

\begin{tabular}{|l|l|l|l|}
\hline Variables & \multicolumn{2}{|c|}{ Statistical Data } \\
\hline $\begin{array}{l}\text { Relationship between Administrative } \\
\text { Workload and Psychological Pressure }\end{array}$ & $\begin{array}{l}\text { Pearson Correlation } \\
\text { Coefficient Value }\end{array}$ & Sig. & $\mathrm{N}$ \\
\cline { 2 - 4 } & 0.46 & 0.01 & 48 \\
\hline
\end{tabular}

Table (4) shows that there is a statistically significant relationship between administrative workload and psychological pressure among coaches of some fitness centers in Amman - Jordan, as the correlation coefficient (0.46) is significant at the significance level (0.01).

The researcher indicated that the coaches perform a lot of works, including training and administrative matters. It may be because the number of coaches working in the centers is inadequate compared to the number of customers who are going to these centers. In addition, it may be due to a number of coaches unqualified to perform their main work in these centers. Therefore, the work will become the responsibility of a few qualified coaches, which makes them feel dissatisfied with their job and exert the great effort without commensurate salary. 
It may also be because they are forced to work long hours and feel that their efforts at work are in vain and that their work is not appreciated, making their training work with customers a bit stressful and jittery. Hegarty, N. (2010) pointed out that the increase in the administrative workload leads to an increase in looking for job opportunities in other places and also results in a loss of concentration at the work and high rate of customer complaints as well as the sense of failure and job dissatisfaction.

The third questions was "Are there statistically significant differences in the level of psychological pressure attributed to the gender variable?".

To answer this question, one - way analysis of variance (ANOVA) was used as shown in Table (5).

Table (5): Differences in Arithmetical Means of the Levels of Psychological Pressure among the Study Sample.

\begin{tabular}{|c|c|c|c|c|c|c|c|}
\hline $\begin{array}{l}\text { Statistical } \\
\text { Indicators } \\
\text { Gender }\end{array}$ & $\mathrm{N}$ & $\mathrm{M}$ & SD & $\mathrm{T}$ & $\mathrm{P}$ & $\mathrm{df}$ & Sig. \\
\hline Female Coaches & 38 & 70.65 & 22.00 & & & & \\
\hline Male Coaches & 12 & 92.50 & 14.03 & 4.83 & 2.67 & 48 & .01 \\
\hline
\end{tabular}

Table (5) shows that $\mathrm{T}$ value is (4.83), which is greater than $\mathrm{P}$ value (2.67) at the significance level (0.01) with degree of freedom (48), indicating that there are statistically significant differences between arithmetical means of coaches (70.65) and mean square (92.50) on psychological pressure measure.

The researcher indicated that from the viewpoint of the study sample the coaching profession does not receive a prominent position in the community, which makes the coaches feel embarrassed to practice this work despite their workloads. It may be because the material aspect does not reflect the great effort exerted by the coaches of both genders. The reason may also be that the female coaches work irresponsibly in comparison with the male coaches who have interest in working as a livelihood. The reason probably is that the employers in these centers sympathize with the female coaches and try to hide their mistakes. Ivancevich, J. (2001) pointed out that the administrative workload shall be distributed fairly among coaches or employees and commensurate with their salary without gender discrimination and that the administrators shall appoint qualified personnel of both genders and provide all the necessities of a decent life Armstrong (2000).

\section{Conclusions}

The aim of the major study was to identify administrative workload and its relationship with psychological pressure among some coaches at fitness centers in Jordan the results indicated that the level of psychological pressure among coaches of both genders was high due to their administrative workload. Furthermore there is a strong correlation relationship between administrative workload among coaches of some fitness centers and psychological pressure. Researcher found that the administrative workload in these fitness centers causes professional psychological pressure. He recommended that reducing the administrative workloads of coaches of both genders though appointing manpower commensurate with the nature of work and it is necessary to pay attention to psychological conditions of coaches of both genders. Finally it is necessary to conduct studies on psychological pressure periodically and regularly to identify the psychological pressure among coaches in these fitness centers and others.

\section{References}

Armstrong, M. (2000). Performance Management: Key Strategies and Practical Guidelines. KoganPage,London, UK.

Ahmad, Amal and Mahmoud, Mariam (2009). Methods of Dealing with Psychological Pressure among Youth University, A Field Study,Damascus University,The Journal of Educational and PsychologicalSciences, Vol. (10), Issue (1). Manama - Bahrain.

Al Byrqdar, Tanheed (2011). Psychological Pressure and its Relationship with Psychological Toughness among Students of the Faculty of Education, The Journal of Researches of the Faculty of Basic Education, Vol. (11), Issue (1).

Bohlander, G. and Snell, S. (2007). Managing Human Resources. Thomson, Australia.

Cheng W-K (2009). An study Of stress sources among college student in taiwan. J Acad Bus Ethic; 2: 1-8

Hegarty, N. (2010). Application of the AcademicMotivation Scale to Graduate School Students, The Journal of Human Resources and Adult Learning 6 (02).

Honeycutt, J., (2000). Knowledge Management Strategies, Washington: Microsoft Press.

Ivancevich, J., (2001). Human resources Management (Irwin, McGraw - Hill).

Schiffman, L., and Konuk, L., (2000). Consumer Behavior, Seventh Edition, New Jersey: Prentice - Hill.

Watson, T. (2005). Organisations, Strategies and Human Resourcing. InLeopold J., Harris, L. and Watson, T.,The Strategic Managing of Human Resources. 1-33, Pearson Education, London, UK.

Wong AC. (2012) . Essentials of psychology. Belmont, CA: Wadsworth 